\title{
Enfermedad de Madelung (Síndrome de Launois-Bensaude)
}

\author{
Madelung's Disease (Launois-Bensaude \\ Syndrome)
}

Presentamos el caso de un varón de 41 años de edad afecto de hepatopatía crónica de etiología alcohólica con antecedentes de tuberculosis pulmonar y seronegativo para el VIH, que admitió una ingesta de unos $400 \mathrm{~g}$ de alcohol al día durante varios años. Fue admitido por recidiva de tuberculosis y tratado con esquema anti bacilar hepatoprotector. Seis años antes había notado aumento del volumen del cuello, de la nuca y de la parte superior del dorso. El examen físico constató masas de consistencia blanda y no dolorosas (Figuras 1 y 2). La tomografía mostró que estas resultaban de acumulación adiposa. (Figura 3) Estos hallazgos son compatibles con Enfermedad de Madelung, una lipomatosis simétrica de etiología desconocida que incide sobre todo en hombres de mediana edad, de la zona mediterránea, frecuentemente asociada al alcoholismo crónico ${ }^{1,2}$. Conocida también por Lipomatosis simétrica benigna, es rara y generalmente benigna aunque se han descrito casos de lipomas que se malignizaron. Su causa es desconocida teniendo el alcohol un papel principal. Algunas hipótesis etiológicas destacan la hipertrofia del tejido adiposo marrón altamente enriquecido con mitocondrias y algunos casos familiares están relacionados con mutaciones de ADN mitocondrial. Además, el alcohol causa lesión directa sobre el metabolismo mitocondrial provocando disminución de la lipolísis y consecuente acumulación adiposa. En el tratamiento es prioritario que los pacientes abandonen el consumo de alcohol pero la regresión de la lipomatosis no ocurre espontáneamente. El tratamiento es quirúrgico indicándose la exéresis de lipomas o liposucción en aquellos de grandes dimensiones, cuando la lipomatosis causa síntomas relacionados como los derivados de constricción de las vías aerodigestivas y por razones estéticas ${ }^{3}$.

\section{Bibliografía}

1. Sokolov M, Mendes D, Ophir D. Madelung's Disease. IMAJ 2010; 12: 253-4;

2. Aragón FJ, Puebla JMM, Pereira TC. Enfermedad de Madelung. Acta Otorrinolaringol Esp. 2011. doi:10.1016/j.otorri.2011.10.00.

3. Ampollini L, Carbognani P. Madelung's disease. N Engl J Med. 2011;364:465

\section{Diagnóstico: Enfermedad de Madelung (Síndrome de Launois-Bensaude)}

P Ricardo Pereira, Ana Jerónimo.

Serviço de Medicina Interna. Hospital Pedro Hispano - ULS de Matosinhos. Senhora da Hora, Portugal

Correspondencia: p.ricardo.o.pereira@gmail.com

Como citar este artículo: Pereira PR, Jerónimo A

Enfermedad de Madelung (Síndrome de Launois-Bensaude). Galicia Clin 2014; 75 (4): 206

Figura 1. Masas adiposas de consistencia blanda

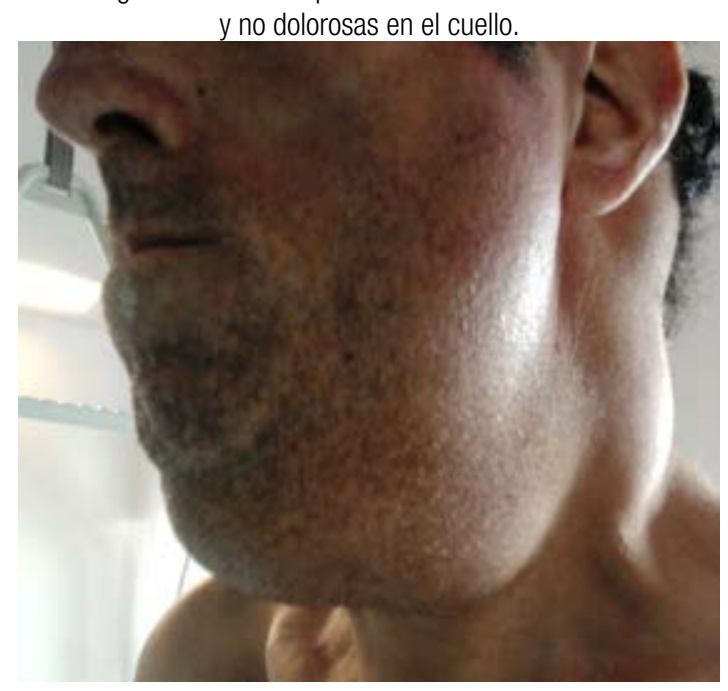

Figura 2. Acumulación adiposa simétrica, respectando la cara.

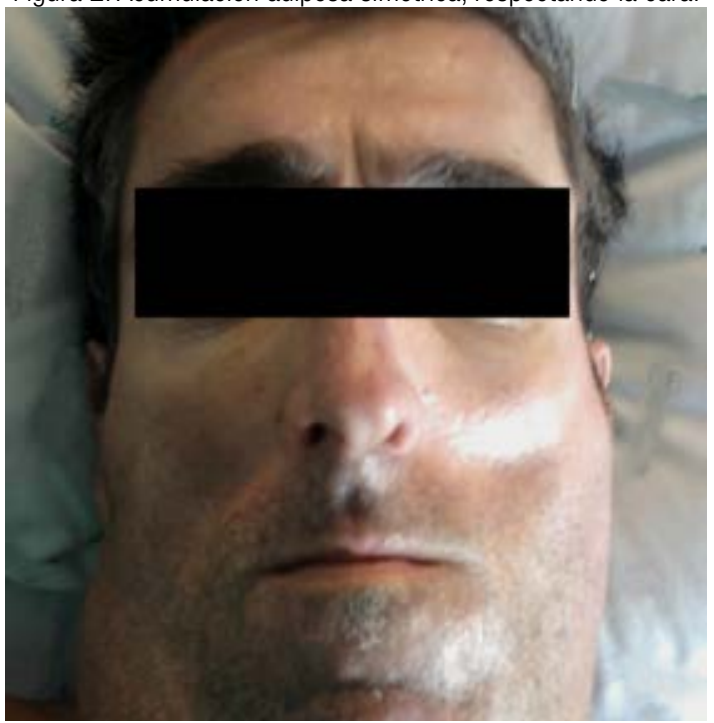

Figura 3. Tejido adiposo en la tomografía computarizada.

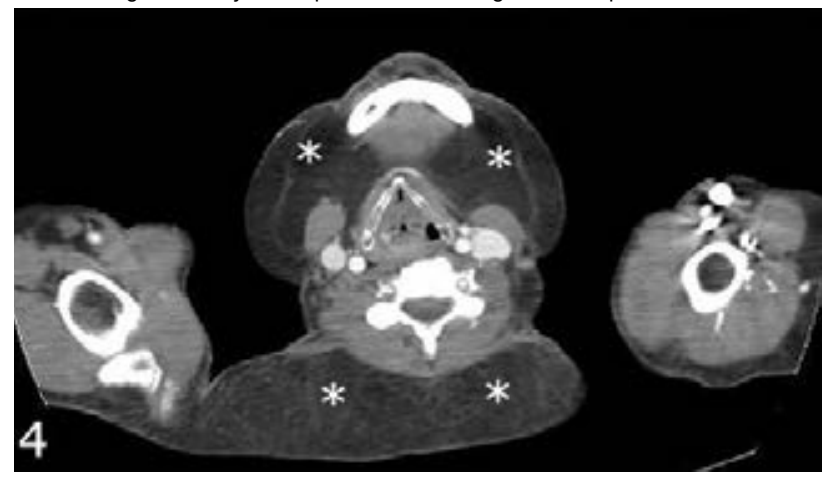

Recibido: 19/08/2014; Aceptado: 24/10/2014 